\title{
A Computação Embarcada, a Plataforma Arduíno e a Internet das Coisas como Tecnologia Assistiva na construção de Mapas Táteis para os Alunos com Deficiência Visual no Processo de Ensino e Aprendizagem
}

\author{
Elias dos S. Silva Júnior ${ }^{1}$, Sérgio C. C. da Silva Pinto ${ }^{2}$, Ruth M. Mariani Braz ${ }^{3}$ \\ ${ }^{1}$ Instituto de Biologia - CMPDI - Universidade Federal Fluminense \\ Campus Valonguinho - Niterói, RJ - Brasil \\ ${ }^{2}$ Instituto de Biologia - CMPDI - Universidade Federal Fluminense \\ Campus Valonguinho - Niterói, RJ - Brasil \\ ${ }^{3}$ Secretaria de Educação do Estado do Rio de Janeiro
}

eliasjk@gmail.com, cresposergio@gmail.com, ruthmariani@yahoo.com.br

\begin{abstract}
The senses are the door to learning and in its absence, remaining and residual senses are stimulated aiming at school performance. Laws ensure the rights of students with Visual Disabilities, but schools are disabled in Assistive Technology that help in their inclusion. The research uses computation in solving this educational problem, through a computational model embedded in a tactile and political map of the Southeast that attends to the specificities of these students, united the senses of touch and hearing. The research proved the increase in the quality and the autonomy of these students in the studies of this Region of Brazil.
\end{abstract}

Resumo. Os sentidos são a porta para a aprendizagem e na sua falta, os sentidos residuais e remanescentes são estimulados visando o desempenho escolar. Leis asseguram os direitos dos Alunos com Deficiência Visual, mas as escolas são deficientes em Tecnologia Assistiva que auxiliam na sua inclusão. A pesquisa utiliza a computação na resolução desse problema educacional, por meio de um modelo computacional embarcado num mapa tátil e político da Região Sudeste que atende as especificidades desses alunos, unindo os sentidos do tato e da audição. A pesquisa comprovou o aumento da qualidade e a autonomia desses alunos nos estudos dessa Região do Brasil.

\section{Introdução}

O processo de aprendizagem, segundo Goldschmidt et al. (2008), é facilitado com a união/estímulo dos sentidos, pois as informações são transmitidas e interpretadas pelo cérebro, sendo captados por células sensoriais, assim, os cinco sentidos são a porta de entrada para a aprendizagem. A exploração dos sentidos auxilia no entendimento dos conteúdos, resultando no sucesso acadêmico dos alunos, sendo fundamental para o discente com deficiência visual transpor as barreiras que a deficiência o impõe. 
Nesse cenário, os conceitos computacionais agregam funcionalidades às Tecnologias Assistivas (TA) e colaboram com Bersch (2017) quando afirma que uma TA é destinada à educação quando beneficia ao aluno na intenção de vencer as barreiras geradas por sua deficiência sensorial, motoras e até cognitivas que interferem no seu processo de ensino e aprendizagem, promovendo uma maior assimilação dos conteúdos.

As políticas públicas destinadas às pessoas com deficiência são determinadas por leis, como por exemplo: a Lei de Diretrizes e Bases [Brasil 1996], Lei $n^{\circ}$ 9394/96, que garante aos discentes, sem distinção, o seu ingresso na rede regular de ensino, dando a preferência em classes comuns e a Lei ${ }^{\circ}{ }^{\circ} 13.146$, Lei Brasileira de Inclusão [Brasil 2015], que as garante condições igualitárias e as suas liberdades fundamentais.

Dias e Santos (2016) afirma que no mundo, segundo a OMS, somos 35 milhões de cegos, além de 246 milhões que perderam a visão parcialmente e $90 \%$ estão em países em desenvolvimento. No Brasil, o IBGE em 2010 publicou que a deficiência visual foi a mais frequente entre os seus entrevistados, sendo 35,7 milhões de pessoas cegas e de baixa visão. Nesse universo 18,8\% alegaram dificuldades para enxergar e utilizam lentes de correção. A pesquisa ainda apontou 506 mil pessoas cegas.

Podemos inferir que esses dados interferem na educação, como relata a matéria de Lontra (2018) do jornal O GLOBO de 31/01/2018 que aponta um aumento da inclusão dos alunos com deficiência na educação brasileira, porém as escolas não têm estruturas para recebê-los. Houve aumento de matrículas desses alunos no ensino, mas as escolas não possuem os recursos mais elementares e muito menos os mais tecnológicos que permitem aos educandos serem incluídos em seu ambiente escolar.

Em resposta a essa deficiência educacional, projetamos um produto que tem a função de atender as necessidades acadêmicas desses alunos, unindo o tato e a audição, através de um modelo computacional embarcado num mapa tátil que materializou os conceitos de design e de Affordances ${ }^{1}$ de Donald Norman que foram somados à teoria da interação entre o ser e o objeto na construção do conhecimento de Jean Piaget.

Nesse contexto, temos como objetivo a construção de um produto, utilizando os fundamentos da Internet das Coisas e sustentada pela Plataforma Arduíno, embarcado num mapa tátil, abordando características políticas da Região Sudeste, visando agregar funcionalidades a esse mapa na intenção de aumentar a qualidade no ensino e promover uma maior autonomia aos estudos dos discentes ouvintes com deficiência visual.

Em consonância com o nosso objetivo, levantamos a hipótese de como a computação embarcada nos mapas táteis, pode propiciar uma maior qualidade no ensino/aprendizagem e autonomia aos estudos das pessoas com deficiência visual.

Essa iniciativa investigativa é de grande importância para os alunos com deficiência visual, pois incentiva e apresenta que é possível propor inovadoras formas de Tecnologia Assistiva, integrando a computação no desenvolvimento de recursos mais tecnológicos e funcionais que atendam as carências desse público para se tornarem protagonistas em seu próprio processo de ensino e aprendizagem e não apenas serem incluídos num ambiente educacional no ato de suas matrículas, conforme prevê a lei.

\footnotetext{
1 "O termo Affordance se refere às propriedades percebidas e reais de um objeto, principalmente as propriedades fundamentais que determinam de que maneira o objeto poderia ser usado." [Norman 2006 p. 33].
} 
VII Congresso Brasileiro de Informática na Educação (CBIE 2018)

Anais dos Workshops do VII Congresso Brasileiro de Informática na Educação (WCBIE 2018)

\section{Fundamentação Teórica}

\subsection{A Deficiência Visual (DV) e a sua relação com o aprendizado}

A DV pode ser classificada, clinicamente, numa escala de cegueira total até o nível de pessoas que não possuem uma visão saudável, mas temos outras formas, a visão residual do aluno pode classificá-lo, a tal ponto, que o professor ao educá-lo, deverá conhecê-lo e explorá-lo em seus potenciais visuais residuais, independente de seu diagnóstico clínico [Figueiredo 2014]. A DV possui diversas especificidades e o desafio é diagnosticar, corretamente, estas pessoas para que atinjam o êxito educacional.

Kastrup (2007) relata em sua pesquisa que o tato e a audição são os sentidos que são mais evoluídos dentre as pessoas que não possuem o sentido da visão em comparação às pessoas que possuem uma visão saudável.

Para que a escola seja inclusiva é primordial o uso adequado das Tecnologias Assistivas que possibilitam aos alunos vencerem as barreiras de suas deficiências.

\subsection{A Tecnologia Assistiva (TA) Incluindo as Pessoas com Deficiência Visual}

$\mathrm{Na}$ visão Cook e Hussey (1995, p. 5) a TA é "uma ampla gama de equipamentos, serviços, estratégias e práticas concebidas e aplicadas para minorar os problemas funcionais encontrados pelos indivíduos com deficiência”. Podemos resumi-la como qualquer recurso que promova o bem estar das pessoas com deficiência.

As TA's disponíveis e mais comuns são: software leitores de tela (JAWS, Virtual Vision e DOSVOX); scanner; software para conversão de texto para voz; áudio livros; Themorform; o sorobã; gravadores; máquina Perkins Braille; Regletes; punções; escrita Braille; lupas e lentes de aumento, bengalas e dentre outros [Bersch 2017].

Utilizamos os conceitos computacionais como TA no desenvolvimento de mapas táteis mais funcionais e tecnológicos.

\subsection{A Computação Embarcada (CE) em Mapas Táteis}

De uma forma geral, Silva Júnior (2018) disserta que o mapa tátil é um recurso que possibilita a pessoa com DV ter uma percepção mais concreta do espaço geográfico, que desenvolve a orientação e a mobilidade na dificuldade visual e por meio do tato.

Em relação à CE, Cirilo (2008) a conceitua como um hardware embutido ao ambiente de forma imperceptível ao usuário, possuindo a capacidade de processar informações desse ambiente, podendo possuir aplicações invisíveis aos seus usuários.

Empregamos a CE no intuito de aumentar os recursos tecnológicos dos mapas táteis para o gerenciamento da união, simultânea, dos sentidos do tato e da audição.

\subsection{A Plataforma Arduíno (PA) como um sistema inclusivo de baixo custo}

A PA é composta por hardware e por software abertos que suportam o desenvolvimento de projetos simples; de baixo custo; compatíveis com os sistemas operacionais populares; de aprendizado fácil; suporta projetos mais complexos; utiliza a linguagem C++; e possui kits que são facilmente encontrados no comércio [Arduíno 2018].

A PA foi fundamental como base do hardware e do software embarcados no mapa tátil, sendo uma arquitetura disponível, de fácil programação e implementação. 
VII Congresso Brasileiro de Informática na Educação (CBIE 2018)

Anais dos Workshops do VII Congresso Brasileiro de Informática na Educação (WCBIE 2018)

\subsection{A Internet das Coisas (IdC) aplicada em Mapas Táteis}

Kahl e Floriano (2012) definem a Computação Ubíqua, como computadores que estão presentes em todos os momentos ajudando aos humanos, sem que ele tenha a percepção dessas ações. Sua importância não esta na abstração, mas na assimilação das informações sem a intervenção de seu usuário e sim pelo ambiente. A Computação Ubíqua é proveniente da união entre a Computação Pervasiva e a Computação Móvel. A primeira sustenta o conceito de ser imperceptível ao usuário. Já a segunda se desloca pelo ambiente e se mantém conectada à sua rede local e/ou a Internet.

Aplicamos os conceitos da $\mathrm{IdC}$, em específico, a Computação Ubíqua na concepção de uma rede de 46 sensores táteis e de uma rede sem fio, permitindo que a união dos sentidos ocorresse através dos símbolos táteis, sendo correlacionados com as áudios-descrições que foram armazenadas, previamente, no produto.

\section{Os Procedimentos Metodológicos}

A Geografia foi escolhida como o modelo desta pesquisa por ser uma área amplamente estudada pelas pessoas com DV, permitindo ao pesquisador a aquisição de requisitos já validados, cientificamente, através das buscas nas bases acadêmicas.

Primeiramente, realizamos uma pesquisa bibliográfica nas bases acadêmicas para obtermos informações sobre as melhores práticas, uso de materiais, as principais funcionalidades e de como produzir mapas táteis que atendessem as especificidades das pessoas com deficiência visual, fornecendo-nos o conhecimento necessário para o desenvolvimento da primeira versão do protótipo experimental do mapa tátil.

De posse dessas informações, desenvolvemos a primeira versão do mapa tátil, embarcando a eletrônica que compõe o hardware do sistema, onde aplicamos as melhores práticas e parâmetros obtidos através de nossas buscas nas bases acadêmicas.

O Instituto Benjamin Constant (IBC) foi o ambiente educacional de campo escolhido para a evolução da pesquisa no processo de validação e avaliação do mapa tátil construído. Nesse ambiente, os Professores de Geografia e os Alunos com DV do $6^{\circ}$ ao $9^{\circ}$ ano do ensino fundamental doaram seu tempo, como participantes e voluntários, para opinarem sobre essa nova proposta de construção para esses materiais.

$\mathrm{Na}$ primeira fase da pesquisa iniciamos a validação do mapa tátil, com a participação de um Professor de Geografia, aplicando o processo da prototipagem evolutiva e por meio de entrevistas livres, estabelecendo uma comunicação para o desenvolvimento de um projeto rápido e básico de um mapa político da Região Sudeste e da Rosa dos Ventos que foi evoluído sem o seu descarte, até que o professor definisse o protótipo como um pré-produto pronto para ser apresentado ao aluno com DV.

Em seguida, desenvolvemos a prototipagem evolutiva com a participação do Aluno com DV do $8^{\circ}$ ano, onde apresentamos o pré-produto e iniciamos uma sequência de entrevistas livres, até que o aluno validasse o pré-produto como um produto final que atendesse as suas especificidades.

$\mathrm{Na}$ segunda fase da pesquisa desenvolvemos a avaliação do mapa tátil, onde contamos com a participação de 03 Professores de Geografia e 10 Alunos com DV do $6^{\circ}$ ao $9^{\circ}$ ano de diversas especificidades, tais como: Alunos cegos e Alunos de baixa visão leve, moderada e severa. 
Neste processo, os 03 Professores de Geografia avaliaram o produto em 17 itens sobre as características e as funcionalidades referentes ao seu desempenho alcançado no processo de ensino e aprendizagem, através de uma entrevista livre, o preenchimento de um questionário aberto e outro fechado e finalizamos com a entrevista semiestruturada.

Os 10 Alunos com deficiência visual avaliaram o produto em 14 itens sobre as características e funcionalidades do mapa tátil sobre o seu desempenho em ajudá-los a transpor as barreiras da deficiência visual. Utilizamos a observação sistemática nãoparticipante, a entrevista estruturada, a entrevista semiestruturada e a entrevista livre.

Em todo o processo investigativo as entrevistas foram gravadas e os relatos dos participantes foram transcritos, os dados compilados e analisados, gerando os resultados relevantes que foram apresentados nessa pesquisa.

\section{Resultados}

O produto foi registrado como material didático junto a Fundação Biblioteca Nacional

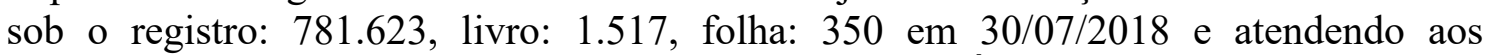
preceitos éticos a pesquisa foi submetida ao Comitê de Ética na Pesquisa da UFF, via Plataforma Brasil, analisada e aprovada, em 29/09/2017 e sob o número 2.304.803.

\subsection{Os Resultados da Revisão Bibliográfica}

Realizamos uma pesquisa nas bases do Google Acadêmico, SciELO e Periódico da CAPES, entre 2016 a maio de 2017, resultando em 25 artigos que publicaram técnicas e materiais para a construção de mapas táteis mais eficazes e eficientes.

Os símbolos táteis são organizados claramente no mapa, facilitando a leitura do Aluno. Eles não devem ser maiores que a palma da mão, nem tão menores que a ponta dos dedos e não devemos produzir mapas táteis maiores que a extensão dos braços dos alunos, evitando um esforço corporal que se torna cansativo no ato da leitura.

A criação de mapas multisensoriais facilita o aprendizado do aluno, pois o conteúdo é diluído pelos estímulos sensoriais proposto pelo mapa. Na falta da visão, todos os outros sentidos devem ser explorados, principalmente do tato e da audição.

O preto, o amarelo, o violeta, o laranja, o azul e o verde são cores utilizadas no produto pelos tons vivos e contrastantes que facilitam a visão dos alunos de baixa visão.

Os formatos e as texturas diferenciadas aumentam a qualidade da leitura a partir do tato dos alunos cegos/de baixa visão severa, facilitando a identificação dos símbolos táteis, da própria Região Sudeste, dos quatro estados dessa região e da Rosa dos Ventos.

É de extrema importância que os recursos educacionais utilizem um Design Universal. Essa iniciativa atende a todos os educandos, independentemente, de suas dificuldades, deficiências e barreiras; e promovem materiais de propósito inclusivo.

Utilizar materiais que não provoquem acidentes aos utilizadores desses mapas.

Os mapas que possuem um sistema de escala bem elaborado fornecem aos seus alunos uma ideia de dimensão entre o mapa e seu tamanho real.

O uso do Braille é obrigatório, pois é a escrita da pessoa com DV. Na escrita em tinta, devemos utilizar um contraste do preto com o fundo branco e fontes ampliadas. 
VII Congresso Brasileiro de Informática na Educação (CBIE 2018)

Anais dos Workshops do VII Congresso Brasileiro de Informática na Educação (WCBIE 2018)

\subsection{A Construção do Protótipo Experimental do Mapa Tátil}

$\mathrm{Na}$ construção da primeira versão do mapa tátil, utilizamos os requisitos obtidos nas bases acadêmicas, os conceitos de design de Donald Norman e a interação ente o ser e o objeto na construção do conhecimento, abordado por Jean Piaget.

Norman (2006) explica a teoria da existência de uma psicologia relacionada aos produtos através do estudo de affordances dos objetos. São propriedades percebidas e reais de um objeto, enfatizando as suas propriedades fundamentais que irão determinar como esse objeto deve ser utilizado. Quando o designer desenvolve um produto aplicando corretamente esse conceito, o usuário não irá necessitar de manual de instruções, pois o design do produto será auto-explicativo em seu uso correto.

Aplicamos o conceito de Norman no intuito de tornar esse produto um recurso educacional intuitivo e de fácil aprendizado, para isso, modelamos o design desde o seu modelo computacional que foi embarcado ao mapa, até na sua aparência de design externo, conforme apresentado na figura 1.

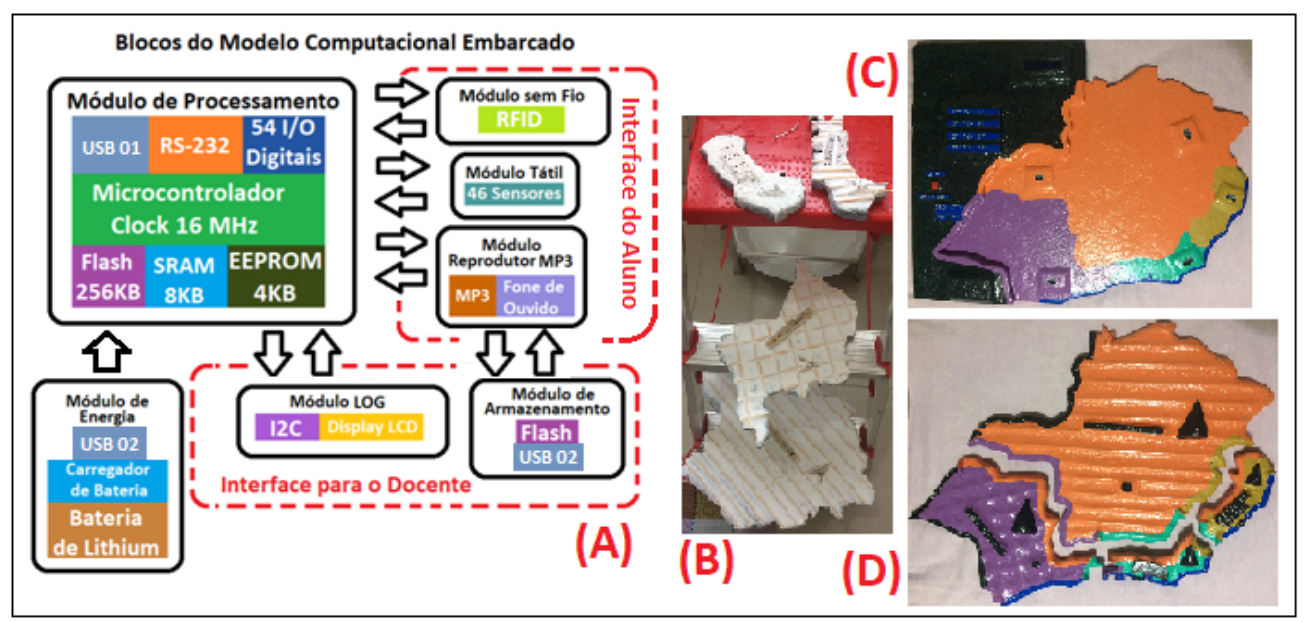

Figura 1. Design Computacional e Estrutural do Mapa Tátil.

Os módulos do sistema computacional, embarcado ao mapa, permitiram ao professor e ao aluno com deficiência visual acessarem as suas interfaces funcionais do sistema de forma estável, conforme ilustrado na figura $1 \mathrm{~A}$.

O modelo computacional é composto pelo módulo de energia que alimenta todos os circuitos; do módulo de processamento que gerencia todos os eventos e informações do sistema; da interface do Professor, onde é possível inserir e atualizar todo o conteúdo do mapa; e da interface do Aluno, ocorrendo a interação de união do tato com a audição.

$\mathrm{Na}$ figura 1B, ilustramos como foram construídas as texturas aplicadas aos 4 estados da Região Sudeste: em Minas Gerais utilizamos linhas horizontais com palitos de churrasco; em São Paulo modelamos diversos losangos, cruzando linhas com palitos de churrasco; no Rio de Janeiro utilizamos linhas verticais com palitos de dente; e no Espírito Santo modelamos a sua textura somente com a massa acrílica.

A Região Sudeste é apresentada na figura $1 \mathrm{C}$, onde ilustramos o seu design de formato, cores, textura e a sua apresentação e podemos afirmar que se trata da Região Sudeste do Brasil. Já na figura 1D, observamos os 4 estados dessa região e podemos analisar as texturas, os formatos, as cores e os símbolos táteis empregados em sua direção norte, suas capitais e o seu nome escrito em Braille. 
VII Congresso Brasileiro de Informática na Educação (CBIE 2018)

Anais dos Workshops do VII Congresso Brasileiro de Informática na Educação (WCBIE 2018)

Utilizamos a teoria de Jean Piaget para estruturarmos os conteúdos acadêmicos do mapa político da Região Sudeste e criar um ambiente de ensino e aprendizagem que permitiu ao aluno conversar com o objeto e o objeto conversar com ele, na intenção dessa conversa estimular a construção do conhecimento.

$\mathrm{O}$ autor explica a sua teoria ao afirmar que:

A inteligência não começa, pois, nem pelo conhecimento do eu nem pelas coisas enquanto tais, mas pelo conhecimento de sua interação, e é ao orientar-se simultaneamente para os dois pólos dessa interação que ela organiza o mundo, organizando a si mesma [Piaget 2001 p. 361].

O design do mapa tátil propõe um ambiente de diálogo com o aluno, pois ao manipular o mapa, imediatamente, é respondido ao aluno esse estímulo gerado pelo tato, proveniente dos sensores. Para cada estímulo, o mapa executa uma áudiodescrição se referindo às características do sensor invocado e a indicação do próximo passo a ser seguido, este processo ocorre durante a sua interação/estudo com o mapa, atribuindo-lhe um significado lógico, assim como explicado por Jean Piaget.

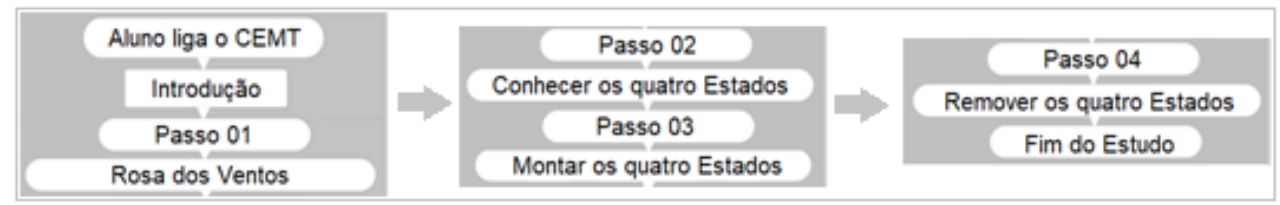

Figura 2. Design Computacional e Estrutural do Mapa Tátil.

$\mathrm{Na}$ figura 2, apresentamos um fluxograma que estrutura os conteúdos sobre a temática da Região Sudeste. O Aluno ao ligar o mapa, inicia-se o estudo ouvindo uma breve introdução e o mapa o direciona para o PASSO 01, onde o Aluno estudará o conceito, funções e aplicações da Rosa dos Ventos; no PASSO 02, o Aluno irá conhecer as características populacionais, econômicas e sociais de cada estado; no PASSO 03 ele montará os 4 estados na Região Sudeste e explorará suas divisas; suas capitais; seu ponto cardeal Norte e o seu nome em Braille; e no PASSO 04, o Aluno removerá cada um dos 4 estados finalizando os estudos proposto pelo produto pesquisado.

Com o desenvolvimento da primeira versão do protótipo, iniciamos o processo investigativo de campo no Instituto Benjamin Constant (IBC).

\subsection{A Validação do Protótipo do Mapa Tátil}

$\mathrm{Na}$ validação do protótipo contamos com a participação do Professor de Geografia como Professor Participante 01 e o Aluno com deficiência visual de baixa visão e que domina a leitura em Braille como Aluno Participante 01.

Apresentamos o protótipo ao Professor Participante 01 e através de uma entrevista livre, perguntamos no que o mapa tátil deveria evoluir para melhor atender as especificidades das pessoas com deficiência visual. O participante nos apresentou os seguintes requisitos: adicionar uma escala em Braille e em tinta ao mapa; adicionar o titulo ao mapa em Braille e em tinta; apresentar a fonte do mapa; usar a fonte APHONT sem o negrito; escrita em tinta preta com fundo branco; avivar a cor verde usado no Rio de Janeiro; e ter o controle da velocidade da voz para o usuário do mapa. 
VII Congresso Brasileiro de Informática na Educação (CBIE 2018)

Anais dos Workshops do VII Congresso Brasileiro de Informática na Educação (WCBIE 2018)

Iniciamos a Prototipagem Evolutiva e a cada requisito satisfeito o Professor validou o processo até que todos pudessem ser analisados e validados. Satisfazemos os 7 requisitos, menos o da velocidade da voz, por limitações de hardware do sistema que não permitiu essa função. O Professor validou o protótipo para ser validado pelo aluno.

O Aluno Participante 01 estudou através do mapa tátil, lhe foi perguntado a mesma questão respondida pelo Professor. O Aluno apresentou os seguintes requisitos: não é possível identificar a cor verde da Rosa dos Ventos; a cor amarela do Espírito Santo não é fácil de identificar; A escrita Braille do Espírito Santo está incorreta; a voz está um pouco rápida; e a dificuldade para montar Minas Gerais na Região Sudeste.

A Prototipagem Evolutiva foi aplicada a cada requisito exposto pelo Aluno onde os seus 5 requisitos foram satisfeitos, melhorando as condições de sua usabilidade.

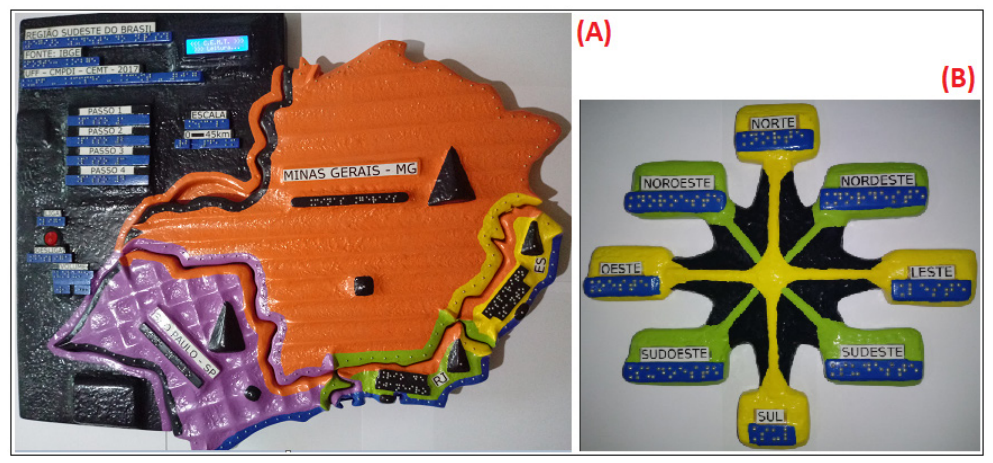

Figura 3. Design final do Produto Mapa Tátil.

O Aluno validou o Protótipo que passou a ser o Produto final da pesquisa (Figura 3A e 3B) pronto para ser avaliado pelos Professores e Alunos.

\subsection{A Avaliação do Produto do Mapa Tátil}

$\mathrm{Na}$ avaliação do produto contamos com a participação de 3 Professores de Geografia e de 10 Alunos com DV que trabalham e estudam, respectivamente, no IBC.

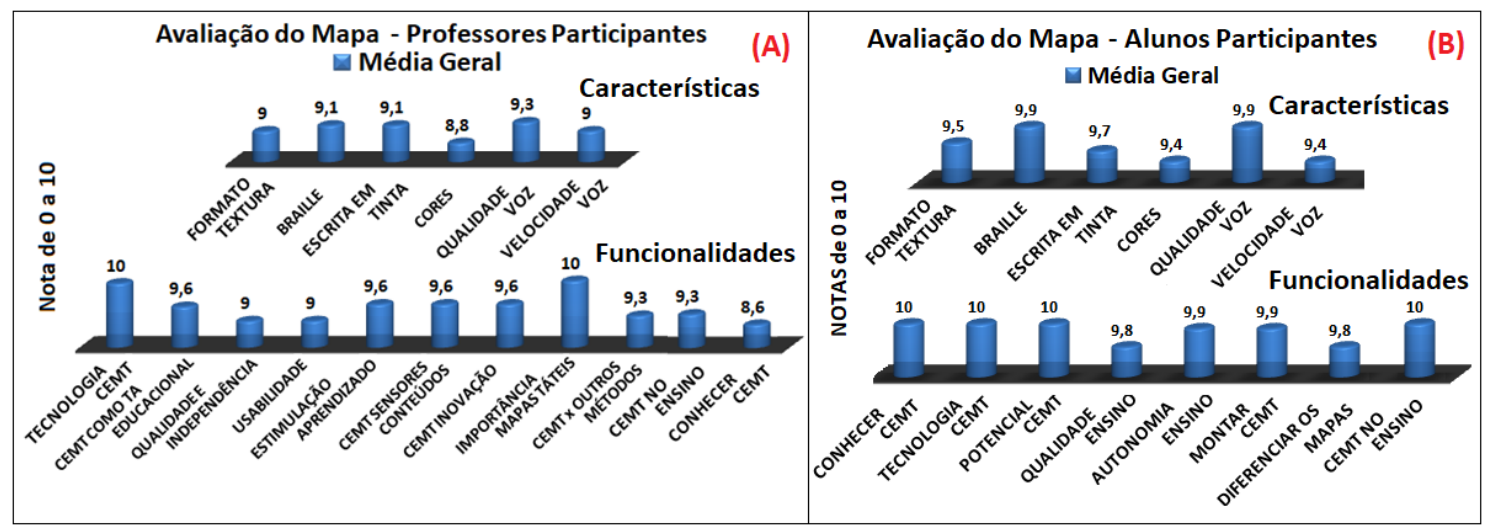

Figura 4. Avaliação Geral dos Professores Participantes e Alunos Participantes.

Os 3 Professores de Geografia, figura 4A, avaliaram de uma forma geral os 6 itens referentes às características do mapa tátil e numa forma mais específica, eles avaliaram cada uma das cores utilizadas, a textura de cada mapa, a escrita em Braile de cada um dos 06 mapas táteis, totalizando 27 itens e 270 pontos possíveis. Na avaliação final alcançamos 244,67 pontos com $90,6 \%$ de aproveitamento real. 
VII Congresso Brasileiro de Informática na Educação (CBIE 2018)

Anais dos Workshops do VII Congresso Brasileiro de Informática na Educação (WCBIE 2018)

As funcionalidades do mapa tátil, figura 4A, foram avaliadas pelos 3 Professores de Geografia em seus 11 itens, totalizando 110 pontos possíveis, obtivemos 104 pontos alcançando 94,54\% de aprovação.

Os Alunos com DV, figura 4B, avaliaram de uma forma geral, os mesmos 6 itens avaliativos que os professores analisaram, referentes às características do mapa tátil e numa forma mais específica, eles avaliaram cada uma das cores utilizadas, a textura de cada mapa, a escrita em Braile de cada um dos 06 mapas táteis, totalizando 27 itens e 270 pontos possíveis. Na avaliação final alcançamos 261,97 pontos com $97 \%$ de aprovação.

No quesito das Funcionalidades, figura 4B, foram 8 itens avaliativos que totalizaram 80 pontos possíveis, pontuamos 79,4 pontos, obtendo um índice de aprovação real de $99,25 \%$.

\section{Conclusões e Trabalhos Futuros}

A Prototipagem Evolutiva nos permitiu a construção de recursos/materiais educacionais mais democráticos e inclusivos, pois proporcionaram tanto aos Professores de Geografia, quanto ao Aluno com DV serem protagonistas no processo de criação e desenvolvimento de um produto em que eles próprios são os potenciais consumidores.

A CE adicionou funcionalidades específicas ao sistema, permitindo uma maior portabilidade e usabilidade aos seus usuários, pois eles não perceberam a existência de um computador plugado ao sistema.

A PA teve condições técnicas de atender as expectativas de um hardware e Software para o projeto, vencendo as barreiras no propósito de incluir as pessoas com DV nos estudos do mapa político da Região Sudeste do Brasil, comprovando a sua eficácia no desenvolvimento de projetos inclusivos a um baixo custo.

Os conceitos da IdC, em conjunto com as redes de sensores, conseguiram com todo esse aparato tecnológico, unir os sentidos da audição e do tato de forma simultânea, permitindo ao aluno com deficiência visual uma maior qualidade e independência em seus estudos.

A qualidade foi entregue ao aluno, através do produto, quando provamos ser possível adicionar um imenso conteúdo sobre a Região Sudeste e fazê-lo estudá-lo no seu tempo, dando-lhe uma maior autonomia em repeti-lo por quantas vezes forem necessário ao seu entendimento pleno do conteúdo.

A CE, a PA e a IdC, Além da metodologia da Prototipagem Evolutiva foram importantes ferramentas para construção desta TA, pois entregaram aos mapas táteis características/funcionalidades que venceram barreiras impostas pela deficiência, atendendo as pessoas com deficiência visual no seu processo de ensino e aprendizagem.

Pretendemos expandir essa técnica para outras áreas, tais como: a matemática, a ciência, a física, a biologia e outras; intensificar os testes; adicionar outras técnicas computacionais na construção de materiais didáticos inclusivos; e apresentar novos exemplos em que a computação contribua no processo de inclusão dos Alunos com DV.

\section{Referências}

Arduino. (2018), https://www.arduino.cc/. Acesso em: 19 de fevereiro, 2018. 
VII Congresso Brasileiro de Informática na Educação (CBIE 2018)

Anais dos Workshops do VII Congresso Brasileiro de Informática na Educação (WCBIE 2018)

Brasil. Lei $\mathrm{n}^{\circ}$ 9.394, de 20 de dezembro de 1996. "Estabelece as diretrizes e bases da educação nacional”. Diário Oficial da União. http://www.planalto.gov.br/ civil_03/leis/L9394.htm. Acesso em: 05 de março, 2017.

. Lei $n^{\circ} 13.146$, de 06 de julho de 2015. "Institui a Lei Brasileira de Inclusão da Pessoa com Deficiência (Estatuto da Pessoa com Deficiência)". Diário Oficial da União, http://www.planalto.gov.br/ccivil_03/_ato2015-2018/2015/Lei/L13146.htm. Acesso em: 05 de janeiro, 2017.

Bersch, Rita. (2017) "Introdução à tecnologia assistiva". Tecnologia e educação: Porto Alegre, p. 1-20, http://www.assistiva.com.br/Introducao_Tecnologia_Assistiva.pdf. Acesso em: 13 de janeiro, 2018.

Cirilo, Carlos Eduardo. (2008) "Computação Ubíqua: definição, princípios e tecnologias”. São Carlos: UFSC, https://docit.tips/download/computaaao-ubaquadefiniaao-princapios-e-tecnologias-carlos_pdf. Acesso em: 09 de maio, 2017.

Cook, A.M. \& Hussey, S. M. (1995) “Assistive Technologies: Principles and Practices”. St. Louis, Missouri. Mosby - Year Book.

Dias, Glaucia Soldati; Santos, Ivan Mota. (2016) “Criação de um Mapa Tátil através da Tecnologia Assistiva: mais Acessibilidade aos Deficientes Visuais com a utilização da Impressão 3D”. Blucher Design Proceedings, v. 2, p. 5386-5397, https://www. proceedings.blucher.com.br/download-pdf/277/24698. Acesso em: 10 de maio, 2017.

Figueiredo, João Ricardo Melo. (2014) “O presente pelo passado: variação verbal em narrativas de deficientes visuais". Rio de Janeiro: Instituto Benjamin Constant.

Goldschmidt, Andrea Inês et al. (2008) “A importância do lúdico e dos sentidos sensoriais humanos na aprendizagem do meio ambiente". Seminário internacional de educação-indisciplina e violência na escola: cenários e direções, Cachoeira do Sul, p. 9-11, http://www.sieduca.com.br/2008/admin/upload/70.doc. Acesso em: 08 de maio, 2017.

Kahl, Marcelo; Floriano, Diogo. (2012) "Computação ubíqua, tecnologia sem limites". Vale do Itajaí, http://www.ceavi.udesc.br/arquivos/id_submenu/387/diogo _floriano_marcelo_kahl_computacao_ubiqua.pdf >. Acesso em: 07 de maio, 2017.

Kastrup, Virgínia. (2007) "A invenção na ponta dos dedos: a reversão da atenção em pessoas com deficiência visual”. Psicol. rev., Belo Horizonte, v.13, n. 1, p. 69-90, http://pepsic.bvsalud.org/pdf/per/v13n1/v13n1a05.pdf. Acesso em: 10 de maio, 2017.

Lontra, Thiago. (2018) “Aumenta inclusão de alunos com deficiência, mas escolas não têm estrutura para recebê-los". O globo, Rio de Janeiro, https://oglobo.globo.com /sociedade/educacao/aumenta-inclusao-de-alunos-com-deficiencia-mas-escolas-naotem-estrutura-para-recebe-los-22348736. Acesso em: 19 de fevereiro, 2018.

Norman, Donald A.(2006) “O design do dia-a-dia”. Rio de janeiro: Rocco.

Piaget, J. (2001) “A Construção do Real na Criança”. 1 ed. São Paulo: Ática.

Silva Júnior, Elias dos Santos. (2018) “A Internet das Coisas e a Plataforma Arduíno como Computação Embarcada em Mapas Táteis: Uma avaliação dessa Tecnologia Assistiva para o ensino das pessoas ouvintes com deficiência visual.". Dissertação (Curso de Mestrado Profissional em Diversidade e Inclusão - CMPDI) Instituto de Biologia da Universidade Federal Fluminense. 